Article

\title{
Personal Assessment of Reasons for the Loss of Global Biodiversity-An Empirical Analysis
}

\author{
Matthias Winfried Kleespies * and Paul Wilhelm Dierkes \\ Bioscience Education and Zoo Biology, Goethe-University Frankfurt, Frankfurt 60438, Germany; \\ dierkes@bio.uni-frankfurt.de \\ * Correspondence: kleespies@em.uni-frankfurt.de; Tel.: +49-69-798-42276
}

Received: 22 March 2020; Accepted: 20 May 2020; Published: 22 May 2020

\begin{abstract}
The UN's sustainable development goals (SDGs), which aim to solve important economic, social, and environmental problems of humanity, are to be supported by education for sustainable development (ESD). Empirical studies on the success of the implementation of the SDGs in the field of education are still pending. For this reason, using the loss of global biodiversity as an example, this study examined the extent to which high school students, teacher trainees in biology, and biology bachelor students can identify the causes of the global biodiversity loss. A new questioning tool was developed and tested on 889 participants. In addition, the relationship between connection to nature and the personal assessment about biodiversity threats was examined. The factor analysis of the scale used showed that 11 out of 16 items were assigned to the intended factor. The comparison between high school students, teacher trainees in biology, and biology bachelor students showed no significant difference in overall assessment of the reasons for global biodiversity loss. When comparing the three risk levels in which the risk factors for biodiversity could be divided, across the three student groups, only minor differences were found. Therefore, a specific education of prospective teachers is necessary, as they have to pass on the competence as multipliers to their students. No significant difference could be found when examining the relationship between connection to nature and the overall scores of the assessment scale for the reasons of biodiversity loss. However, it was found that people who felt more connected to nature were more capable of assessing the main causes of risk for global biodiversity, while people who felt less connected to nature achieved better scores for the medium factors.
\end{abstract}

Keywords: biodiversity loss; environmental knowledge; connection to nature; connectedness to nature; INS; sustainable development goals (SDGs); education for sustainable development (ESD)

\section{Introduction}

In 2015, the 17 sustainable development goals (SDG) were ratified as part of Resolution 70/1 of the General Assembly of the United Nations [1]. These SDGs were the follow-up goals to the eight millennium development goals (MDGs) of the year 2000 that were an attempt to reduce global poverty, especially in developing countries, by 2015 . Notable progress has been made in many countries, and some have even achieved most of the MDGs [2]. The main goal of reducing the number of people who have to survive on less than $\$ 1.25$ a day by half was achieved before 2015, partly because of China's strong economic growth [3].

As successors to the MDGs, the SDGs have the task of initiating actions that are crucial for mankind and the planet [1]. The 17 objectives cover different topics and are closely related. From the point of view of environmental and sustainability education, objective number 15 is of particular importance. It aims to protect terrestrial ecosystems, promote their restoration and sustainable use, and put an end to the loss of biodiversity [4]. In particular, the objectives and targets of SDG 15 mention 
the conservation of biodiversity in different ecosystems, its appreciation, its sustainable use, and the reduction of its decline. Biodiversity also plays a special role in the indicators for assessing the success of SDG 15 [5].

Biodiversity is defined as the variability among living organisms [6]. It is usually classified in genetic diversity (diversity within a species), in species diversity (diversity between species), and ecosystem diversity (diversity of habitats) [7]. More recent definitions include not only the number of genotypes, populations, and ecosystems, but also the relative frequency, range of functional traits, spatial distribution, and vertical diversity [8].

Today, biodiversity is at greater risk than ever before. Prognoses for the 21st century predict a progressive decline $[9,10]$. The number of threatened species is also increasing from year to year. In 2019, the International Union for Conservation of Nature (IUCN) classified 30,178 of the evaluated 112,432 species as threatened with extinction [11]. The current extinction rate is about 100 to 1000 times higher than the background rate of extinction [12]. The background rate is in the order of 0.1 extinctions per million species-years (E/MSY), while the current extinction rate is about $100 \mathrm{E} / \mathrm{MSY}$ [13]. This persistent loss has strong negative consequences for ecosystems. For example, the loss of biodiversity reduces the stability of an ecosystem and decreases its productivity and many ecosystem services that are important for humans are closely related to biodiversity [14]. Particularly in marine ecosystems, biodiversity loss reduces the ability of the oceans to provide food, maintain water quality, and recover from ecosystem disruptions [15]. Important ecosystem services are lost not only in water, but also on land. Insects are responsible for $75 \%$ of the pollination of human food plants. Both the abundance and diversity of pollinators are currently declining rapidly worldwide, which has a major impact on food production. The loss of small vertebrates that act as pesticides could result in crop losses of up to $37 \%$ [16]. In addition, the loss of invertebrates could reduce nutrient cycling and decomposition in ecosystems [16]. It is fatal that particularly poor regions are affected by the loss of ecosystem services [8]. In addition to these arguments, there are a number of ethical reasons for preserving biodiversity. For example, the intrinsic value of nature or to preserve biodiversity for future generations [17].

The reasons for the loss of biodiversity are extremely complex. In particular, land use change, climate change, atmospheric $\mathrm{CO}_{2}$ concentration, nitrogen deposition, and invasive species are considered to be the greatest threats to global biodiversity $[10,18,19]$. In the meantime, overexploitation must now also be counted among the main threats to global biodiversity [20-22]. In the following, the six main reasons for the decline of global biodiversity will be presented.

The main threats to biodiversity on land and in freshwater ecosystems are land use change and overexploitation [19].

- The largest factor currently influencing global biodiversity is land use change [18]. It has a drastic effect on biodiversity by changing the structure and composition of ecosystems and thus, also biodiversity [23]. Since the intensity of land use has increased drastically in recent decades, natural habitats have also declined dramatically. For this reason, many species have already become extinct on a global scale [24-26]. The main reason for land-use changes is cattle breeding, although oilseed production is also growing rapidly [27].

- Overexploitation is one of the main causes of the global decline in biodiversity [20-22] and poses a major threat, particularly to biodiversity in aquatic ecosystems. Here, the excessive exploitation and extraction of organisms from aquatic ecosystems plays a major role and causes lasting damage to biodiversity. Especially the use of trawl gear has a strong negative impact on the entire ecosystem [28]. However, overexploitation is also a threat to terrestrial ecosystems. Animals are excessively hunted for various reasons or trees are felled for raw material extraction. About $40 \%$ of vertebrates suffer from overexploitation [29]. One-third of the birds and mammals threatened with extinction can be attributed to overuse. Overexploitation is often linked to the destruction or fragmentation of habitats [30]. 
- The consequences of climate change are currently the subject of intense discussions. While land-use change is currently the main cause of biodiversity loss, climate change is likely to become an increasingly important factor over the next 40 years [31]. Climate change is closely linked to the increasing amount of $\mathrm{CO}_{2}$ [32] or other greenhouse gases [33] in the atmosphere. The main victims of climate change will be species that have not yet been affected by human activity and whose habitats are not yet threatened [34]. The predictions vary, but most assume that climate change will have fatal consequences for biodiversity. The worst-case scenarios assume a sixth mass extinction in earth's history [35].

The threat of invasive species and the various types of pollution are also major causes of biodiversity loss [19].

- Invasive species are a major problem for endemic biodiversity. Organisms are either accidentally introduced into foreign habitats, deliberately released, or escaped from animal husbandry. Some of these alien species cope better with the living conditions in their new habitat and displace endemic species, leading to lasting damage to ecosystems [36]. The damage caused by invasive species is difficult to estimate, but it is assumed that in the United States alone, about 50000 species have immigrated, causing damage of approximately $\$ 137$ billion annually [37].

- In addition to invasive species, the influence of nitrogen deposition on biodiversity is also often underestimated. The input of nitrogen from industry and agriculture is the third largest threat to terrestrial biodiversity after land use change and climate change. The effects of nitrogen exposure are assumed to be difficult to reverse [38]. Analyses show that, especially in biodiversity hotspots, nitrogen emissions are $50 \%$ higher than the global average. This could result in critical loads being exceeded in these areas in particular, which would have fatal consequences for biodiversity [39]. The accumulation of nitrogen compounds is the main reason for the change in species composition in various ecosystems, as the increased nitrogen concentration interferes with the competition between species. Other effects, such as the toxicity of nitrogen compounds, also play a role [40].

Besides these six main reasons for the global decline in biodiversity, there are a number of other factors that have a negative impact on biodiversity. In certain ecosystems, these factors may even have a major impact. These include world population growth [41,42], meat production [43,44], habitat fragmentation [45,46], plant monocultures [47], or hormone-like substances (endocrine disruptors) in the environment $[48,49]$.

One important approach to raising people's awareness of the issue of biodiversity loss is environmental education [50,51]. It is an instrument to support sustainable development [52] and thereby also to achieve the SDG [53]. Therefore, in 2017, the UNESCO published a strategy paper describing learning contents that should contribute to the achievement of the 17 individual goals. For Goal 15, for example, the reasons for the threat to biodiversity and human connection to nature are proposed as topics [54].

For a long time, one of the basic goals of environmental education was to impart knowledge about environmental issues to teach people how to solve environmental problems [55]. However, the link between environmental knowledge and ecological behavior is controversial [56]. Although, the influence of knowledge on behavior was confirmed in some studies [57-59]. Knowledge about environmental issues and action strategies can have a positive influence on environmental behavior [60]. Nevertheless, this old paradigm is repeatedly criticized in current research and is even called a myth by some [61]. Moss et al. [62] found that the correlation between knowledge and pro-environmental behavior is very small. Otto and Pensini [63] also confirm that knowledge only has a small effect, if any, on environmental behavior. Although the influence of knowledge on behavior is controversial, knowledge is important to understand the issue of biodiversity and the decline of biodiversity [64]. In order to grasp this difficult and interdisciplinary topic, knowledge about species, extinctions, and ecosystem issues is essential [65]. 
Biodiversity and its threats also play an important role in educational research. There are numerous studies on this topic, both among students and teachers. Lindemann-Matthies and Bose [66] discovered in a survey of schoolchildren and adults that $60 \%$ have not yet heard of the term biodiversity. Most of those questioned considered the main source of information on this topic to be the media rather than schools. Furthermore, the local plant diversity was greatly overestimated. In contrast, Fischer and Young [67] found out in a series of focus group discussions that members of the general public have rich mental concepts of biodiversity independent of their knowledge. These include food chains, balances, and human-nature interactions. Yorek et al. [68] conducted semi-structured interviews and discovered that high school students tend to understand biodiversity as a holistic concept that focuses on people. Details such as energy flow and nutrition relationships were neglected. In a survey of pupils aged between 16 and 18, Menzel and Bögeholz [69] discovered that most of those interviewed were expressing ecological or economic aspects of biodiversity loss. Students with an ecological point of view often based their opinions on wrong facts and had problems to feel solidarity and compassion for people in an ecological resource conflict. In addition, the students were often unaware of the loss of biodiversity at local or global level. Through environmental education programs, it is possible to promote students' understanding of biodiversity. The positive effect of an environmental education program in which primary school students were taught to recognize the number and diversity of species on their way to school has been demonstrated [70].

Overall, it can be seen that students have some basic understanding of biodiversity, but there are gaps and differences. This could be related to the understanding and training of teachers.

Although teachers see biodiversity as an important subject for teaching, are well informed about the topic, and pass on important knowledge to their students, the teaching concepts often lack a comprehensible and linked understanding of biodiversity [71]. Dikmenli [72] reports that biology teacher trainees know the basic aspects of biodiversity, but there are deficits in some points. For example, in the conceptual framework of biodiversity, the diversity of ecosystems and species was often considered, but genetic diversity was not. In a study on teacher training in four European countries, Lindemann-Matthies et al. [73] discovered that due to time constraints, the main focus in teacher training is often on scientific aspects of biodiversity. Teaching approaches and teaching skills therefore fall by the wayside. As a result, teachers are not sure how to integrate the topic into their lessons, they lack examples, and appropriate expertise [74]. Falkenberg and Babiuk [75] were able to find a similar result in a Canadian case study: There is no systematic and focused preparation of teachers for teaching sustainability. Lindemann-Matthies [76] also came up with an interesting result: Teachers are more motivated to carry out activities such as outdoor activities within the framework of biodiversity education if they have had such experiences in their own school time or in their teacher training.

Navarro-Perez and Tidball [77] concluded in their literature review on challenges for biodiversity educators, that one of the most important starting points is the establishment of connection to nature.

The concept of connection to nature is defined as the "extent to which an individual includes nature within his/her cognitive representation of self" [78] (p. 67) and is a frequently used construct in environmental education research. Numerous studies have shown that there is a positive relationship between pro-environmental behavior and connection with nature [79-81]. Connectedness to nature is a predictor for more sustainable behavior $[82,83]$ and shows a positive correlation with appropriate environmental behavior [84]. Environmental education programs often focus on increasing connection to nature [85-87]. This raises the question of whether nature-connected people also have other competences in relation to biodiversity in addition to more environmentally friendly and sustainable behavior. In this study, we will investigate whether people with a higher degree of connection to nature could better assess the reasons for global biodiversity loss than people with a lower degree of connection to nature. A personal assessment can provide information about whether a person considers a certain factor to be relevant or not. In our context, we asked how strongly people assess the influence of certain factors on global biodiversity. In contrast to a concrete knowledge survey, such a 
personal assessment can be measured on a Likert scale. This allows for a gradation that would not be possible with multiple choice questions, for example. Hence, the procedure can provide information on whether the relevance of a factor has been correctly identified, over-, or underestimated. It could be assumed that people with a higher degree of connection to nature, due to their higher attachment to the environment, have a better understanding of the reasons for the loss of biodiversity.

In addition, this study will use a newly developed test instrument to check whether the causes of the threat to global biodiversity can be correctly assessed and how well biology interested high school students, biology teacher trainees, and biology students in comparison can assess these causes of biodiversity loss. This procedure can be used to determine which group of participants can give a more accurate assessment and where there is still room for improvement. It could be expected that groups of people with a science education (biology teacher trainees and biology students) can provide better assessments than high school students.

\section{Materials and Methods}

\subsection{Developing A Measurement Instrument for the Personal Assessment of Biodiversity Loss}

In order to determine how well high school students, teacher trainees, and biology students can assess the causes of global biodiversity loss, it was necessary to develop a new test instrument. For this reason, 16 potential factors were selected and their impact on the global biodiversity should be rated by the participants on a 5 -point Likert scale. The scale ranged from 1 (minor influencing factor) to 5 (major influencing factor). We divided the selected factors into three groups based on the current literature on biodiversity decline: Firstly, the main reasons (major influencing factors) for the global loss of biodiversity, which were identified by Sala et al. [18] and extended by other researchers [20,21]. These are land use change, $\mathrm{CO}_{2}$ concentration in the atmosphere, nitrogen deposition, climate change, invasive species, and overexploitation. For the second group, five factors were selected, which are often mentioned in the literature as influencing factors with a strong negative impact on biodiversity but are not one of the main causes of global biodiversity loss mentioned above (medium influencing factors). These chosen factors are world population growth, intensive livestock farming, habitat fragmentation, plant monocultures, and hormone-like substances (endocrine disruptors) in the environment. The third group consists of five factors that we have selected and whose influence on global biodiversity plays a rather negligible role (minor influencing factors). However, some of the factors are repeatedly discussed in different contexts. These include nitrogen oxide emission, which is currently the subject of much debate because of the air pollution in cities, noise pollution from factories and traffic, the use of genetic engineering, hiking through nature reserves, and electro smog. The task emphasized that the influence of the factors on global biodiversity should be assessed (Table A1).

\subsection{Evaluation of the Results of the Scale}

A point system was used to evaluate the scale. A person was awarded a whole point if he or she could correctly estimate the influence of a factor on a Likert scale. In order to consider a correct tendency positively, partial points were awarded. The different scoring between the factors was selected in such a way that, if the factors were selected purely by chance, with the same probability for each box, the same average statistical score (0.4) would be achieved for each item. The scoring according to the three risk levels is shown in Figure 1. To calculate the total score of a person the achieved points of each item were summated, so a total of 16 points could be achieved. 


\begin{tabular}{|c|c|c|}
\hline Major influencing factor & Little influence & $\begin{array}{l}\text { Strong } \\
\text { influence }\end{array}$ \\
\hline Medium influencing factor & Little influence & $\begin{array}{l}\text { Strong } \\
\text { influence }\end{array}$ \\
\hline Minor influencing factor & Little influence & $\begin{array}{l}\text { Strong } \\
\text { influence }\end{array}$ \\
\hline
\end{tabular}

Figure 1. Evaluation system of the scale according to the three threat groups.

\subsection{Measuring Connection to Nature: The INS-Scale}

The Inclusion of Nature in Self Scale (INS) is a graphical single item measuring instrument to determine the connection to nature of a person. It was developed by Schultz [78] on the basis of the Inclusion of Other in Self Scale by Aron et. al [88]. The scale consists of seven circle pairs that differ in their degree of overlap. One circle represents nature, the other the person self. The scale ranges from no overlap (no connection to nature) to a complete overlap (one with nature). The tool is regularly used to evaluate environmental education programs [85-87] and shows a high positive correlation with other testing instruments for connection to nature $[89,90]$. Connection to nature is an important factor to explain human behavior in relation to nature. Thus, connectedness to nature correlates with ecologically sustainable behavior [82]. In addition, conservation behavior [83,91] strengthens the connection to nature, while a low connection to nature leads to a lack of pro-environmental behavior [92]. Connectedness to nature is a predictor of personal happiness [93] and wellbeing [94,95].

\subsection{Participants}

A total of 889 persons in Germany were surveyed ( $55.8 \%$ female, $43.7 \%$ male, $0.5 \%$ no answer). Approximately half of the participants (50.7\%) were high school students from local schools with biology as basic or major course. The students were in the last two years of their school education, which they will complete by obtaining the general matriculation standard (age mean $=17.46$ ). At the time of the survey, the students should have already studied the topic of biodiversity at school according to the guidelines of the local curricula. They completed the questionnaire at events organized by the department of Bioscience Education and Zoo Biology of the Goethe University in Frankfurt. In order to prevent the program from influencing the participants, the questionnaires were completed before the actual program began. These programs include, for example, guided zoo tours or student laboratory days. For their participation, the groups received a discount on the participation fee. Prior to the survey, the parents were informed in writing about the questionnaire and asked for their written consent. If individual students did not take part in the survey, the whole group still received the discount. The remaining participants (49.3\%) were students of the Goethe University Frankfurt with a biological focus. One hundred and eighty-eight were teacher trainees in biology (age mean $=22.44$; semester $\left._{\text {mean }}=3.74\right)$ and 250 bachelor students in their freshman year biology $\left(\right.$ age $_{\text {mean }}=20.36$ ). Participation in all surveys was voluntary and data protection regulations were met. The survey period was the winter semester 2018/2019.

\subsection{Analysis}

All statistical analysis was executed using IBM SPSS 24. To analyze the relationship between the 16 possible threats to biodiversity, a principal component analysis (PCA) with orthogonal rotation (varimax) was performed, after the Kaiser-Meyer-Olkin test and Barlett test verified sampling adequacy. All examined variables were tested for normal distribution using the Kolmogorov-Smirnov test. The Kruskal-Wallis test was applied to compare the results of high school students, teacher trainees, and biology students. When the Kruskal-Wallis test showed a significant result, a pairwise comparison was made using a post hoc test with Bonferroni correction. The effect size (r) was calculated according to Fritz, Morris, and Richler [96]. To make our results comparable with other studies, $r$ was converted to Cohen's d using the formula $\mathrm{d}=\frac{2 r}{\sqrt{1-r^{2}}}$ by Bronstein et al. [97]. To observe the relation between 
connection to nature and the assessment of the reasons for global biodiversity loss the Spearman correlation was calculated, and additional Kruskal-Wallis tests were applied to assess the differences between the degrees of natural connection.

\section{Results}

The Barlett test was significant $(\mathrm{p}<0.001)$ and the Kaiser-Meyer-Olkin test verified sampling adequacy $(\mathrm{KMO}=0.854)$, so the requirements for a PCA were met. The PCA with varimax rotation forced the extraction of three-factors to reflect the theoretical assumption of the scale (a separation in a major, medium, and minor influencing factor). The first factor accounted for $28.23 \%$, the second factor for $9.81 \%$, and the third factor for $8.28 \%$ of the variance (Table 1; Figure 2).

Table 1. Result of the principal component analysis with orthogonal rotation for the 16 threats to biodiversity. Values above 0.3 are printed bold.

\begin{tabular}{ccccc}
\hline & Factor $\mathbf{1}$ & Factor $\mathbf{2}$ & Factor 3 & Mean Value \\
\hline Nitrogen oxide emission & $\mathbf{0 . 7 4 2}$ & 0.238 & 0.060 & 4.06 \\
Atmospheric $\mathrm{CO}_{2}$ & $\mathbf{0 . 7 2 7}$ & 0.169 & 0.183 & 4.24 \\
Nitrogen deposition & $\mathbf{0 . 6 9 0}$ & 0.085 & 0.088 & 4.57 \\
Climate change & $\mathbf{0 . 6 6 5}$ & 0.101 & 0.112 & 4.52 \\
Genetic engineering & 0.156 & $\mathbf{0 . 7 6 3}$ & -0.033 & 3.30 \\
Entering nature reserves & 0.060 & $\mathbf{0 . 6 5 4}$ & 0.213 & 2.79 \\
Electromagnetic pollution & $\mathbf{0 . 3 7 0}$ & $\mathbf{0 . 6 3 2}$ & 0.046 & 3.39 \\
Hormone-like substances & 0.094 & $\mathbf{0 . 5 0 2}$ & $\mathbf{0 . 3 6 6}$ & 3.63 \\
Factory noise & $\mathbf{0 . 3 0 1}$ & $\mathbf{0 . 4 3 0}$ & 0.285 & 3.42 \\
Livestock farming & $\mathbf{0 . 3 3 0}$ & $\mathbf{0 . 4 5 7}$ & 0.122 & 3.87 \\
Changes in land use & $\mathbf{0 . 3 0 1}$ & -0.099 & $\mathbf{0 . 6 6 9}$ & 4.54 \\
Overexploitation & 0.148 & 0.049 & $\mathbf{0 . 6 5 1}$ & 4.40 \\
World population growth & 0.029 & 0.165 & $\mathbf{0 . 6 0 2}$ & 3.94 \\
Habitat fragmentation & 0.229 & 0.149 & $\mathbf{0 . 5 5 7}$ & 4.19 \\
Monoculture & -0.096 & $\mathbf{0 . 4 2 8}$ & $\mathbf{0 . 4 8 6}$ & 3.59 \\
Invasive species & -0.030 & 0.298 & $\mathbf{0 . 4 6 4}$ & 3.69 \\
\hline
\end{tabular}

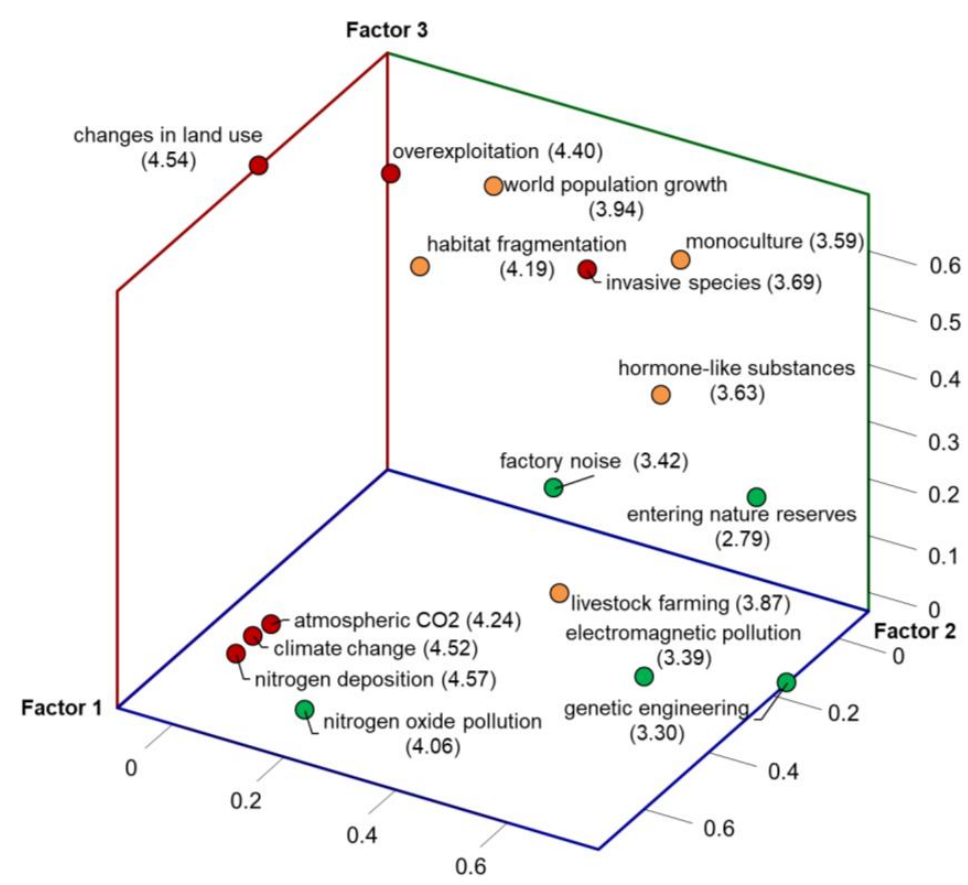

Figure 2. The results of the three-factor solution of the analysis presented in a three-dimensional coordinate system. The graphical illustration shows the separation of the items into a three-factor structure. The color of the items indicates if they are a major (red), medium (orange), or minor (green) influencing factor for global biodiversity. The value in brackets is the mean value. 
The Kolmogorov-Smirnov test showed no normal distribution for all tested variables $(p<0.001)$. Therefore, non-parametric statistical methods were used.

The Kruskal-Wallis test of the overall scores showed no significant difference between the three education levels $(p=0.068)$. The same applied to the achieved scores for the high influencing factors from the theory $(\mathrm{p}=0.414)$. For the medium influencing factors from the theory the Kruskal-Wallis test showed a significant result $(\mathrm{p}=0.02)$. The post hoc comparison with Bonferroni correction revealed a significant difference $(p=0.039)$ between high school students and biology students. The calculated effect size is $d=0.189$. For the minor influencing factors from the theory the Kruskal-Wallis test was significant $(\mathrm{p}=0.002)$. The post hoc comparison showed a difference between the teacher trainees and biology students $(p=0.001)$ with an effect size of $d=0.341$ (Figure 3 ).

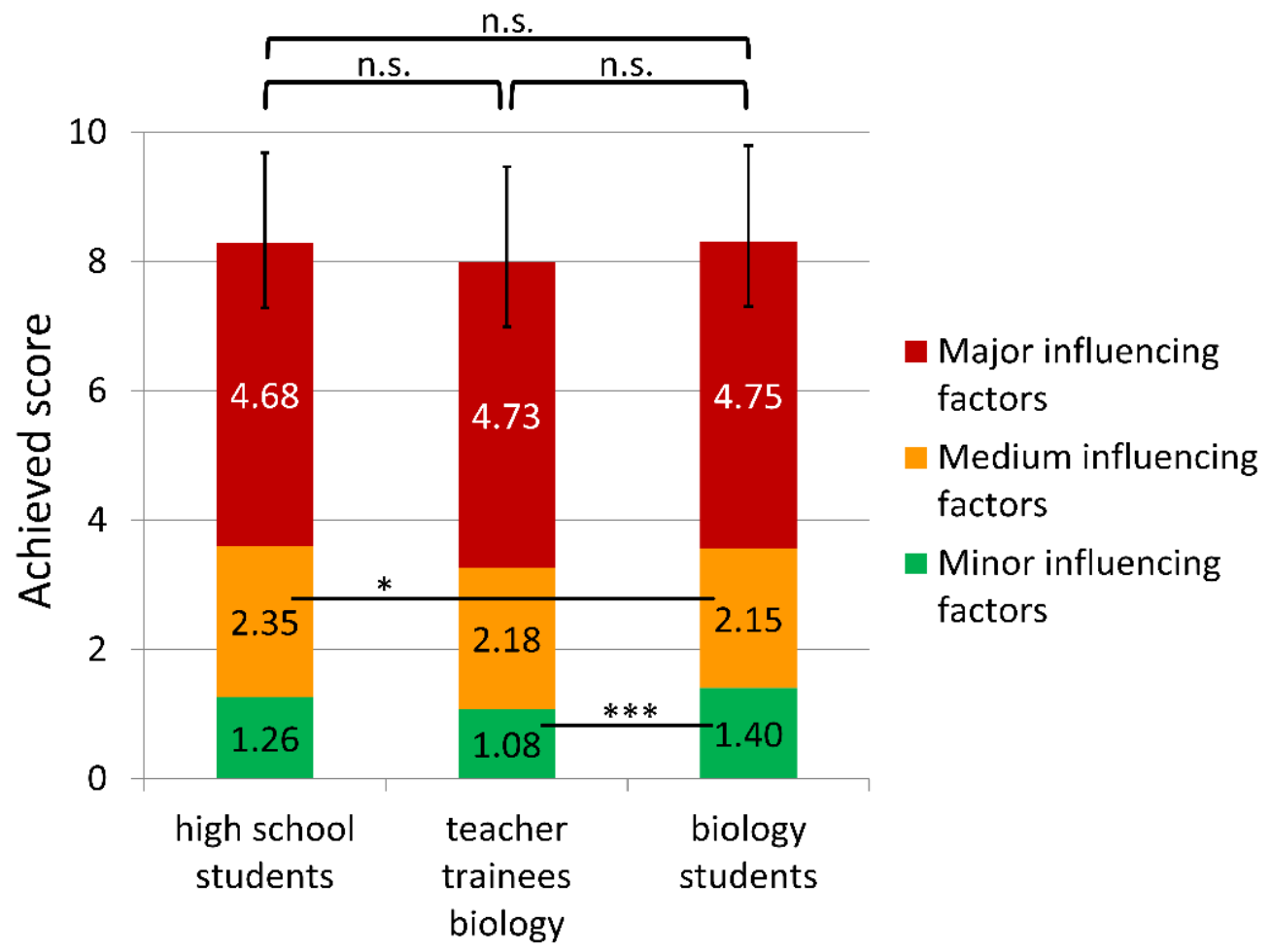

Figure 3. The scores of the potential reasons for global biodiversity loss split by influencing factors and education level. A maximum of six points could be achieved for the major influencing factors, while a maximum of five points was possible for the medium and minor influencing factors. The analysis showed no significant differences in overall scores between the three test groups. In the three sub-categories, a significant difference in the medium influencing factors between high school students and biology students was found, as well as between teacher trainees biology and biology students in the minor influencing factors. Significant shifts are marked with ${ }^{*} p \leq 0.05,{ }^{* *} p \leq 0.01,{ }^{* * *} p \leq 0.001$.

The Spearman correlation between the biodiversity loss assessment scale and connection to nature was $r=-0.060(p=0.075)$. The comparison between the scores for major, medium, and minor influencing factors over the different levels of connection with nature shows a highly significant difference for major and medium factors $(\mathrm{p}=0.001)$. The minor influencing factors show no significant difference between the levels of connection to nature $(p=0.052$; Figure 4$)$. 


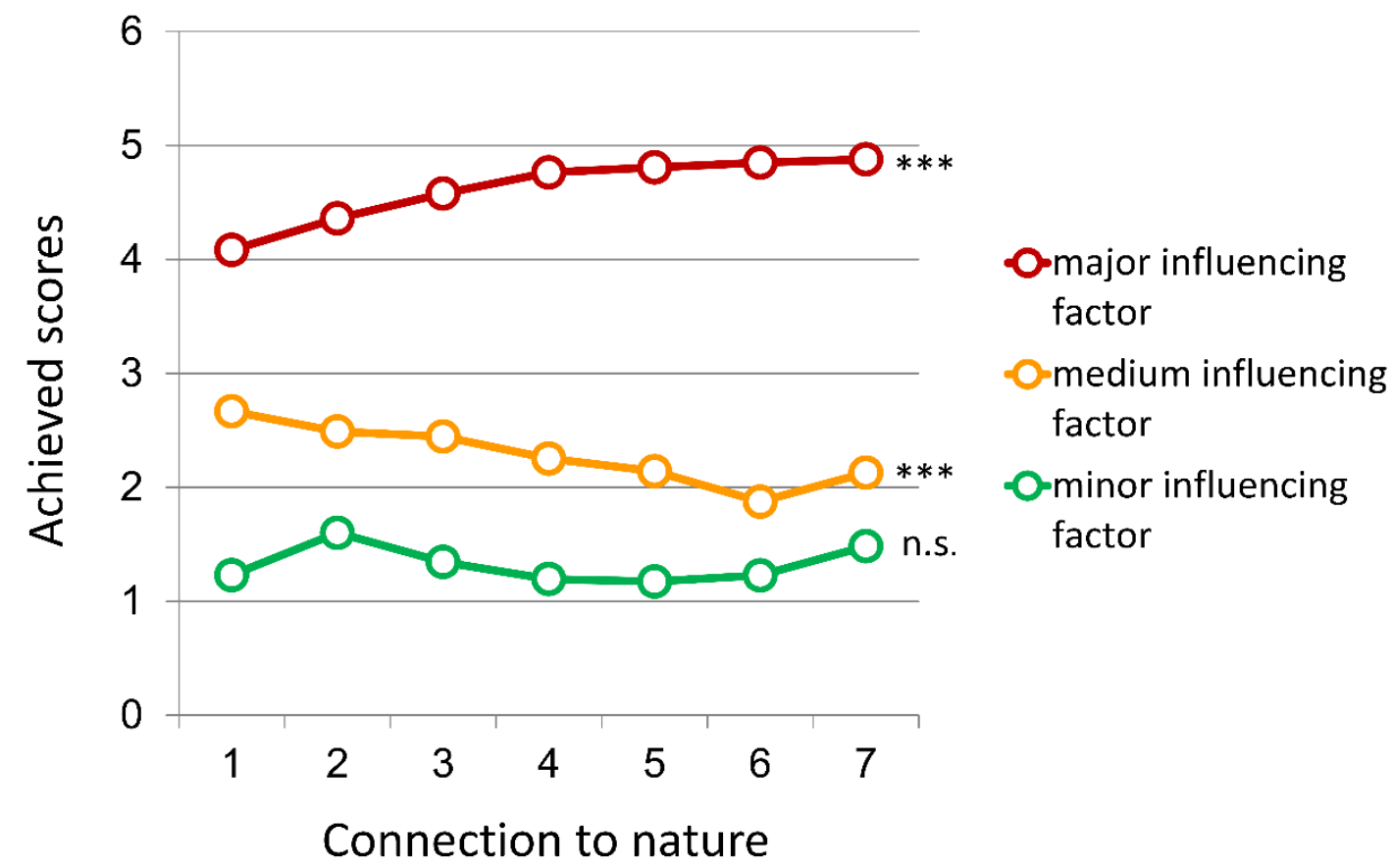

Figure 4. The scores achieved for the three threat levels assumed in the theory, categorized according to their connection to nature. Significant shifts of the Kruskal-Wallis test are marked with ${ }^{*} p \leq 0.05$, ** $p \leq 0.01,{ }^{* * *} p \leq 0.001$.

\section{Discussion}

\subsection{Factor Structure of the 16 Items}

The 16 items show, as expected, a distribution among the three factors that represent the three levels of threat to biodiversity. Eleven of the 16 items are clustered according to the respective level of threat. The remaining five items that were not assigned to the expected threat level are nitrogen oxide emission, land use change, invasive species, industrial livestock farming, and overexploitation.

Nitrogen oxide emission, actually a minor factor of influence on global biodiversity, shows a high factor loading on the same factor as climate change, atmospheric $\mathrm{CO}_{2}$ concentration, and nitrogen deposition. This means that there is a high statistical relationship between these variables and the participants rate the nitrogen oxide load similarly to some of the main biodiversity threats. The high mean value (4.06) confirms this assumption. One reason for this misjudgment could be the current reporting and media attention to this issue. At the beginning of 2018, the Bundesverfassungsgericht (one of the highest courts in Germany) ruled that diesel driving bans in cities are permissible in order to comply with the legal limit value for nitrogen oxides [98]. As a result, the topic was discussed continuously and received a great amount of media attention. In 2018, for example, the German television news reported more about diesel and nitrogen oxides than about the Brexit or the Football World Cup [99]. This constant media presence of the topic and the catchword nitrogen oxides may have led to the fact that the study participants no longer regarded nitrogen emission as a primary human toxicological problem $[100,101]$, but at the same time assumed that it was a threat to global biodiversity.

While the nitrogen oxide emission was rather overestimated, the influence of invasive species was underestimated. It was not considered by the participants as one of the main threats for the loss of biodiversity. One possible reason could be the lack of knowledge about invasive species. In a study at Brookfield Zoo, more than $50 \%$ of the participants reported that they have little or no knowledge about invasive species [102]. In addition, many people have little knowledge about the extent and number of invasive species [103]. Often, it is not the replacement of endemic species that is regarded as the biggest problem of invasive species, but the inconveniences that arise for humans and the destruction 
of habitats. Opinions are divided on how to deal with invasive species. Almost as many people are in favor of their conservation as of their elimination [102]. Moreover, not all invasive species are evaluated equally. While aesthetic or large species are considered worth preserving [103], smaller and unattractive species such as rodents, possums, scorpions, snakes, and some plants are often considered undesirable [104]. The mixture of a lack of knowledge and acceptance of certain invasive species may have led the respondents to the survey to be unable to properly assess the risks to biodiversity.

In addition to invasive species, the currently largest influencing factor on global biodiversity, land-use change [18], was assigned to the same factor in the factor analysis as many medium influencing factors. The same applies to overexploitation. However, the mean value of land use change $(\mathrm{M}=4.54)$ and overexploitation $(\mathrm{M}=4.40)$ indicates that these factors were not underestimated. The assignment to this factor is probably due to the proximity of the content of the neighboring items. A change in land use is often accompanied by fragmentation of habitats, overuse, and overexploitation. It is therefore quite possible that the participants assumed a connection for these factors and therefore assessed them similarly. Another indication of this is the proximity of the three items in the questionnaire. The fragmentation of habitats and the change in land use followed each other (items 7 and 8). The overexploitation also followed shortly after at item 12 .

Surprisingly, industrial livestock farming showed a high loading on the same factor as the five comparative variables with low impact on global biodiversity. Industrial livestock farming has a noteworthy effect on global biodiversity. For example, intensive animal husbandry emits greenhouse gases that exacerbate climate change [105] and mass livestock farming is a direct cause for the progressive change in land use and the fragmentation of habitats [106]. A possible explanation for the incorrect classification, which some participants in the study gave orally after the survey, could be that factory farming was only seen as an animal welfare problem. According to this argumentation, it would make no difference to biodiversity whether the same amount of animals are kept in mass animal husbandry or in ecologically sustainable husbandry, since the same amount of greenhouse gases or garbage is produced. What seems conclusive at first glance can be refuted with a small calculation example from Germany: In 2016, the area used for agriculture was 16.7 million hectares, which corresponds to just over $50 \%$ of the total area of Germany [107]. The cultivation of forage crops takes up about $60 \%$ of this area with 10 million hectares. The majority of forage crops for animals is cultivated in conventional agriculture ( 91\%) [108]. In order to produce organic meat, the EU Regulation (EG) No. 834/2007 Art. 5 (k) [109] prescribes that animals must be fed with feed from organic farming. It should be noted that organic farming in Germany is only about $50 \%$ as productive as conventional farming [110]. This means that an area of more than 20 million hectares would be needed to grow the same amount of feed that is currently produced in conventional agriculture. Feed production alone would exceed the current agricultural area in Germany and cover more than $50 \%$ of the country's total area. This does not include the increased space requirement of sustainably kept animals, but only the change caused by feed production. This small sample calculation shows that it would not be possible to keep and supply this number of animals in Germany ecologically. Only intensive livestock farming makes it possible to keep this large number of animals and produce meat in these quantities. For this reason, intensive livestock farming is a causal problem not only in terms of animal welfare, but also in terms of the loss of biodiversity.

\subsection{Evaluating Group Differences by Educational Level with the New Developed Test Instrument}

The measuring instrument was designed in a way that for each item between 1 and 0.5 (for medium influencing factors) or between 1 and 0.25 (for major and minor influencing factors) points could be achieved. If the questionnaire had been completed without understanding and only at random, with the same probability for each box, an average value of 6.4 points would have been achieved:

Major/minor influencing factors: $\left(\frac{1}{5} \times 1\right)+\left(\frac{1}{5} \times 0.75\right)+\left(\frac{1}{5} \times 0.25\right)=0.4$

Medium influencing factors: $\left(\frac{1}{5} \times 0.5\right)+\left(\frac{1}{5} \times 1\right)+\left(\frac{1}{5} \times 0.5\right)=0.4$

$0.4-16=6.4$ 
The mean value of all three groups was between 7.99 and 8.30. This value was above 6.4. Accordingly, each group had some understanding of the reasons for biodiversity loss. Overall, there was no significant difference in the biodiversity assessment scale between the three groups (high school students, biology teacher trainees, and biology bachelor students). It would have been expected that bioscience students (both teacher trainees and bachelor students) would achieve higher scores than high school students due to their science education. However, this is not the case. This finding is probably based on the content structure of biology studies in the first semesters. Here, the focus is on basic knowledge of the structure and function of organisms and the diversity of habitats. The loss of biodiversity and its consequences are not the main focus, but are treated only marginally, if at all. These contents will only be taught in the later course of biology studies.

The results are consistent with previous research findings. The results show that the assessment of the reasons for the loss of biodiversity is not directly related to their scientific knowledge [67], or in our case to the level of their scientific education. The participants of the study seem to be able to assess the reasons for risk to a certain degree, but a really precise assessment could not be achieved by students, biology teacher trainees, or bachelor biology students. This could be due to the fact that the concept of biodiversity is understood rather holistically, but details such as material cycles or energy flow are not taken into account [68]. However, it is precisely the understanding of such processes that would be necessary in order to be able to accurately assess factors such as nitrogen deposition. The limited understanding of the different levels of biodiversity [72] can also contribute to the misjudgment of factors such as invasive species. To a certain extent, the lack of difference between the scores of high school students and biology teacher trainees confirms the statement from Lindemann-Matthies et al. [73] that teacher training provides too little information and skills on the subject. At least in the first semesters, there seems to be no sufficient preparation of teacher trainees for the topic of biodiversity loss. Similar results were already noted for teacher trainees in Canada [75].

The comparison of the major influencing factors between the three groups shows no significant difference. Each group achieved a similarly high score in this category (4.68 to 4.75 out of 6). This means that, regardless of educational level, there was a good assessment of the main causes of global biodiversity loss. The reason for this is probably the high presence of these issues in society. A significantly lower score was achieved by all three groups in the assessment of the medium factors (2.15 to 2.35 out of 5). The mean values of the individual items indicate that these factors were overestimated rather than underestimated (between 3.59 and 4.19). The significant difference between high school students and biology students is only marginal. The $p$-value $(p=0.039)$ is just within the significant range and the strength of the effect is small, according to the common interpretation according to Cohen [111] with $\mathrm{d}=0.189$. A possible explanation for the occurring significance is the sample size. Due to the large sample size, it is possible that small and actually unimportant effects reach statistical significance [112].

The lowest score in all three groups was achieved for the minor influencing factors (1.08 to 1.40 out of 5). A higher score of 2.0 would have been achieved by randomly selecting the checkboxes. This shows that even factors that currently and globally play only a minor role for biodiversity loss were specifically overestimated by the study participants of all groups. There are certainly several possible reasons for this finding. People base their assessment on information that they have learned and stored in their memory. In particular, current topics, which are also very present in the media, are quickly available. Many topics that are covered in the media are subject to evaluation, both in a positive and negative direction. With regard to negative reporting, people tend to overestimate the probability of these topics [113]. Many people are familiar with the exhaust NO emissions scandal, noise pollution, radiation exposure, or genetic manipulation, as these factors are repeatedly discussed negatively in society. As a result, their impact on global biodiversity loss has probably been overestimated.

Biology students achieved a slightly better result than biology teacher trainees although both groups have to take the same biology courses in their freshman year at university. Students who decide to study biology for a bachelor's degree probably do so out of interest in the subject. Since teacher 
trainees in Germany usually study two different subjects and have to attend a number of other courses in addition to their studies. The division into two subjects means that teacher trainees have less time to deal with topics relevant to biology. In addition, it is not certain that the teacher trainees have chosen biology teaching as a subject simply out of interest. Often other reasons are given why people have chosen to become teachers. For example, that useful and influential work for the public wanted to be done, that working conditions (such as holidays and working hours) were attractive or that they wanted to work with children [114]. Therefore, it is also not guaranteed for biology teacher trainees that the subject is really chosen out of interest. However, it must also be taken into account that the effect is only small and therefore the difference is relatively low.

Overall, the results show that there is a general need to improve the understanding about the causes of global diversity loss. There are gaps in identifying the reasons for biodiversity loss, particularly in the identification of factors that have only a moderate or minor influence. For biology teacher trainees, it would be particularly important to accumulate more knowledge about these factors, since knowledge is particularly important for understanding biodiversity and the biodiversity crisis [64]. Better teacher training in their professional practice has a multiplier effect on the students [115]. In teacher training, focused preparation should take place [75], skills and knowledge should be imparted [73], practical teaching examples on the topic should be given [74], and experiences should be passed on [76]. In addition to this, the next generation of teachers sits among today's students. Good teaching experience can lay the basis for good teaching in the future [76]. For this reason, more courses focusing on the protection of species, nature, and the environment should be offered during teacher training. This topic should also be an integral part of biology lessons at school to educate as many people as possible. People see the loss of biodiversity as one of the most likely and influential global risk factors [116].

\subsection{Connection to Nature and Assessment of the Reasons for Biodiversity Loss}

The first assumption would be that people with a higher affinity to nature could better assess the reasons for the loss of global biodiversity because of their positive relationship to nature. Our results show, however, that there is an insignificant and slight negative correlation between the connection to nature and the overall score of the survey instrument on biodiversity loss $(r=-0.060)$. This means that there is overall no significant link between connection to nature and assessment about the causes of global biodiversity loss.

The detailed analysis between the scores for major, medium, and minor influencing factors over the different levels of connection to nature, however, shows a different picture. There is no significant difference in the minor influencing factors in relation to nature connectedness. This means that the degree of connection to nature is not relevant for the assessment of the minor influencing factors. In contrast, the major and medium influencing factors show a highly significant difference with opposite tendencies. With increasing connection to nature, the score for the major influencing factors increases and reaches a plateau with medium values. This indicates that persons with a higher connection to nature are more capable, to some degree, of assessing the main reasons for biodiversity loss. The medium influencing factors show an opposite result. People with a lower affinity for nature achieve a better result with these factors than people with a high connection to nature (Figure 4). This means that people that are closer to nature are particularly good at estimating the high influencing factors, while the medium influencing factors are better estimated by people who are not so connected to nature.

The reason that nature-connected people perform slightly worse, especially in the medium influencing factors, could be due to a combination of two reasons. Firstly, the group of medium influencing factors receives special attention in school curricula. The increase in the world population, the emerging challenges and consequences for the environment, and the resulting increase in resource consumption is represented in the local curricula of various subjects, such as politics [117] and geography [118]. For example, livestock farming is not only a biological issue, but also an ethical 
or religious one [119]. Therefore, all participants in our study came into contact with these topics during their school career. As mentioned before, when a topic is reported negatively, people tend to overestimate the probability of its occurrence [113]. Secondly, nature-connected people have a special relationship with nature: They show more pro-environmental behavior and attitudes and were more concerned about environmental problems [82-84,120,121]. This particular concern about environmental issues may have led to an overestimation of the reasons in this group in particular. However, the two tendencies for medium and high influencing factors compensate each other in the overall assessment, so that there is no significant difference in the overall score.

In summary, it seems that overall connectedness to nature is no guarantee for a better estimation. This result confirms the results of previous studies. Otto and Pensini [63] found an equally small but positive correlation between connection to nature and environmental knowledge $(r=0.13)$. Very similar results were found by Cheng and Monroe [81] $(r=0.13)$ and Roczen [122].

This only small correlation between connection to nature and environmental knowledge can be explained by the factors that lead to an increase in connection to nature. Although environmental education is also a possibility to raise the connection to nature [85-87], the time a person spends in nature is the deciding factor $[78,82,83,91,123,124]$. Spending time in nature can potentially encourage people to become more involved with the topic, but this does not necessarily lead to an increase in understanding. As a result, a higher degree of connection with nature does not guarantee an increase in knowledge about environmental topics nor, as in this case, a better assessment of the reasons for global biodiversity loss.

\section{Limitations}

Although the study was performed with great care, it is necessary to address some limitations. It is important to note that our classification of the threats to biodiversity into the three groups is a snapshot of the current state of the literature. However, the reasons for global biodiversity loss are dynamic and change over time. For example, while in 2000, overuse was not yet counted among the most important factors [18], its impact has increased significantly in recent years and it is now one of the main causes of global biodiversity loss [20-22]. In the future, the consequences of climate change are likely to become the biggest biodiversity threats [31]. The close connection between the various factors also makes the classification more difficult. The increase in the world population can serve as an example here: It is possible that it could rise to over 12 billion people by 2100 [125]. This increase would probably also lead to an increase in other factors such as climate change, $\mathrm{CO}_{2}$ production, or land use change. The evaluation of these dynamic and complex processes on a 5-point-Likert scale should therefore be interpreted with caution.

The order in which the items were arranged may also have had an influence on the participants' assessment. Especially if the participants' own opinion or an evaluation is asked for, as in this case, it is possible that items that were in the questionnaire earlier have an influence on items that come after.

One methodological limitation is the survey group. Most of the respondents were in the age group between 16 and 25 years and interested in natural sciences. Both high school students and university students had chosen a biological focus. It would be recommended for the following studies to compare the knowledge about biodiversity loss of different groups. For example, younger pupils or students with different focuses. Other age groups could also be surveyed.

\section{Conclusions}

The newly developed threat to biodiversity scale shows that, on average, the participants have a good assessment of the main factors influencing global biodiversity. Some factors in the factor analysis showed deviations, such as nitric oxide pollution. A possible explanation for this finding could be the public attention to this topic.

Against expectations, there were no significant differences between different levels of education. An analysis of the three threat levels between the groups also showed that there were only small 
differences, if any. It is therefore necessary to better educate future teachers about the causes of biodiversity loss, as they will later act as competence multipliers for their students. Nevertheless, the results of the three test groups are positive, since each group came on average above the random score of 6.4 .

Only an insignificant correlation could be identified between overall assessment about biodiversity threats and connection to nature, which confirms the results of previous studies. In addition, however, we found that people with a high degree of connection to nature were particularly good at assessing the main reasons for biodiversity loss, while people with a lower degree of connection to nature were better at identifying the medium influencing factors.

Author Contributions: Conceptualization, M.W.K. and P.W.D.; methodology, M.W.K. and P.W.D.; validation, M.W.K.; formal analysis, M.W.K.; investigation, M.W.K.; writing-original draft preparation, M.W.K.; writing-review and editing, M.W.K. and P.W.D.; visualization, M.W.K. and P.W.D.; funding acquisition, P.W.D. All authors have read and agreed to the published version of the manuscript.

Funding: This study was partly supported by the Opel-Zoo Foundation Professorship in Zoo Biology from the "von Opel Hessische Zoostiftung".

Acknowledgments: The authors would like to thank Jennifer Gübert for her contribution to the data collection.

Conflicts of Interest: The authors declare no conflict of interest.

\section{Appendix A}

Table A1. Threat to biodiversity scale. The 16 items used in the survey in German with the English translation.

\begin{tabular}{|c|c|c|}
\hline & German Items & English Translation \\
\hline Task & $\begin{array}{l}\text { Die Biodiversität (die Vielfalt der Arten, die Vielfalt von } \\
\text { Ökosystemen, genetische Vielfalt) ist heute weltweit } \\
\text { einemmassiven Wandel unterworfen. Bitte bewerten } \\
\text { Sie, wie stark die folgenden Gründe für den Rückgang } \\
\text { der globalen Biodiversität verantwortlich sind. }\end{array}$ & $\begin{array}{l}\text { Biodiversity (the diversity of species, the diversity of } \\
\text { ecosystems, genetic diversity) is today undergoing } \\
\text { massive global change. Please assess the extent to } \\
\text { which the following reasons are responsible for the } \\
\text { decline in global biodiversity. }\end{array}$ \\
\hline 1 & $\begin{array}{l}\text { Umweltverschmutzung (z. B. durch Zunahme der } \\
\text { Stickstoffbelastung) }\end{array}$ & $\begin{array}{c}\text { Environmental pollution (e.g. due to increase in } \\
\text { nitrogen deposition) }\end{array}$ \\
\hline 2 & $\begin{array}{l}\text { Invasive gebietsfremde Arten (Arten, die sich } \\
\text { außerhalb ihres ursprünglichen Lebensraums rasch } \\
\text { vermehren und einheimische Arten verdrängen) }\end{array}$ & $\begin{array}{c}\text { Invasive alien species (species that rapidly } \\
\text { reproduce outside their original habitat and displace } \\
\text { native species) }\end{array}$ \\
\hline 3 & Hormonähnlichen Substanzen in der Umwelt & Hormone-like substances in the environment \\
\hline 4 & Stickoxidbelastung (z. B. durch Dieselfahrzeuge) & Nitrogen oxide emission (e.g. from diesel vehicles) \\
\hline 5 & Lautstärke von Fabriken und Fahrzeugen & Factory and vehicle noise \\
\hline 6 & Massentierhaltung & Mass livestock farming \\
\hline 7 & $\begin{array}{l}\text { Zerschneidung von Lebensräumen (z. B. durch } \\
\text { Straßen, Zäune, ...) }\end{array}$ & Fragmentation of habitats (e.g. by roads, fences, ...) \\
\hline 8 & $\begin{array}{l}\text { Veränderung der Landnutzung durch den Menschen } \\
\text { und daraus resultierender Zerstörung von } \\
\text { Lebensräumen (z. B. durch Abholzung, ...) }\end{array}$ & $\begin{array}{l}\text { Changes in land use by humans and the resulting } \\
\text { destruction of habitats (e.g. through deforestation, ...) }\end{array}$ \\
\hline 9 & Klimawandel & Climate change \\
\hline 10 & Gentechnik & Genetic engineering \\
\hline 11 & Elektrosmog & Electromagnetic pollution \\
\hline 12 & $\begin{array}{l}\text { Übernutzung (z. B. durch Überweidung, } \\
\text { Überfischung, ...) }\end{array}$ & $\begin{array}{c}\text { Overexploitation (e.g. due to overgrazing, } \\
\text { overfishing, ...) }\end{array}$ \\
\hline 13 & Erhöhte $\mathrm{CO}_{2}$-Konzentration in der Atmosphäre & Increased atmospheric $\mathrm{CO}_{2}$ concentration \\
\hline 14 & $\begin{array}{c}\text { Betreten von Naturschutzgebieten (z. B. beim } \\
\text { Wandern) }\end{array}$ & Entering nature reserves (e.g. while hiking) \\
\hline 15 & Anstieg der Weltbevölkerung & World population growth \\
\hline 16 & Pflanzliche Monokulturen & Monocultures of plants \\
\hline
\end{tabular}




\section{References}

1. United Nations. Resolution Adopted by the General Assembly on 25 September 2015. Transforming Our World: The 2030 Agenda for Sustainable Development; A/RES/70/1, 25.9 2015; United Nations General Assembly: New York, NY, USA, 2015.

2. Sachs, J.D. From Millennium Development Goals to Sustainable Development Goals. Lancet 2012, 379, 2206-2211. [CrossRef]

3. Gaffney, O. Sustainable Development Goals: Improving human and planetary wellbeing. Glob. Chang. 2014, 82, 20-23.

4. United Nations. UN General Assembly's Open Working Group Proposes Sustainable Development Goals; United Nations: Rio de Janeiro, Brazil, 2012.

5. Economic and Social Council. Report of the Inter Agency and Expert Group on Sustainable Development Goal Indicators; E/CN. 3/2016/2/Rev. 1*; United Nations: New York, NY, USA, 2016.

6. Dahiya, M.P. Biodiversity Conservation; Pragun Publications: New Delhi, India, 2006.

7. Krishnamurthy, K.V. Textbook of Biodiversity; Science Publishers: Enfield, NH, USA, 2003.

8. Díaz, S.; Fargione, J.; Chapin, F.S.; Tilman, D. Biodiversity loss threatens human well-being. PLoS Biol. 2006, 4, e277. [CrossRef]

9. Pereira, H.M.; Leadley, P.W.; Proença, V.; Alkemade, R.; Scharlemann, J.P.W.; Fernandez-Manjarrés, J.F.; Araújo, M.B.; Balvanera, P.; Biggs, R.; Cheung, W.W.L.; et al. Scenarios for global biodiversity in the 21st century. Science 2010, 330, 1496-1501. [CrossRef] [PubMed]

10. Leadley, P. Biodiversity Scenarios: Projections of 21st Century Change in Biodiversity and Associated Ecosystem Services; A Technical Report for the Global Biodiversity Outlook 3; CBD Technical Series 50; Secretariat of the Convention on Biological Diversity: Montreal, QC, Canada, 2010.

11. IUCN. The IUCN Red List of Threatened Species. Version 2019-3.2019. Available online: http://www. iucnredlist.org/ (accessed on 9 October 2019).

12. Pimm, S.L.; Russell, G.J.; Gittleman, J.L.; Brooks, T.M. The future of biodiversity. Science 1995, 269, $347-350$. [CrossRef] [PubMed]

13. Pimm, S.L.; Jenkins, C.N.; Abell, R.; Brooks, T.M.; Gittleman, J.L.; Joppa, L.N.; Raven, P.H.; Roberts, C.M.; Sexton, J.O. The biodiversity of species and their rates of extinction, distribution, and protection. Science 2014, 344, 1246752. [CrossRef] [PubMed]

14. Cardinale, B.J.; Duffy, J.E.; Gonzalez, A.; Hooper, D.U.; Perrings, C.; Venail, P.; Narwani, A.; Mace, G.M.; Tilman, D.; Wardle, D.A.; et al. Biodiversity loss and its impact on humanity. Nature 2012, 486, 59-67. [CrossRef]

15. Worm, B.; Barbier, E.B.; Beaumont, N.; Duffy, J.E.; Folke, C.; Halpern, B.S.; Jackson, J.B.C.; Lotze, H.K.; Micheli, F.; Palumbi, S.R.; et al. Impacts of biodiversity loss on ocean ecosystem services. Science 2006, 314, 787-790. [CrossRef]

16. Dirzo, R.; Young, H.S.; Galetti, M.; Ceballos, G.; Isaac, N.J.B.; Collen, B. Defaunation in the Anthropocene. Science 2014, 345, 401-406. [CrossRef]

17. Hågvar, S. Preserving the natural heritage: The process of developing attitudes. Ambio 1994, 23, 515-518.

18. Sala, O.E.; Chapin, F.S.; Armesto, J.J.; Berlow, E.; Bloomfield, J.; Dirzo, R.; Huber-Sanwald, E.; Huenneke, L.F.; Jackson, R.B.; Kinzig, A.; et al. Global biodiversity scenarios for the year 2100. Science 2000, 287, 1770-1774. [CrossRef] [PubMed]

19. IPBES. Summary for Policymakers of the Global Assessment Report on Biodiversity and Ecosystem Services of the Intergovernmental Science-Policy Platform on Biodiversity and Ecosystem Services; IPBES Secretariat: Bonn, Germany, 2019.

20. Secretariat of the Convention on Biological Diversity. Global Biodiversity Outlook 3; Secretariat of the Convention on Biological Diversity: Montreal, QC, Canada, 2010.

21. The Environment Agency. Biodiversity. Available online: https://www.eea.europa.eu/soer-2015/europe/ biodiversity (accessed on 10 January 2020).

22. Maxwell, S.L.; Fuller, R.A.; Brooks, T.M.; Watson, J.E.M. Biodiversity: The ravages of guns, nets and bulldozers. Nature 2016, 536, 143-145. [CrossRef] 
23. Martínez, M.L.; Pérez-Maqueo, O.; Vázquez, G.; Castillo-Campos, G.; García-Franco, J.; Mehltreter, K.; Equihua, M.; Landgrave, R. Effects of land use change on biodiversity and ecosystem services in tropical montane cloud forests of Mexico. For. Ecol. Manag. 2009, 258, 1856-1863. [CrossRef]

24. Gutman, G.; Janetos, A.C.; Justice, C.O.; Moran, E.F.; Mustard, J.F.; Rindfuss, R.R.; Skole, D.; Turner, B.L.; Cochrane, M.A. Land Change Science. Observing, Monitoring and Understanding Trajectories of Change on the Earth's Surface; Remote Sensing and Digital Image Processing 6; Springer: London, UK, 2004.

25. Maitima, J.M.; Mugatha, S.M.; Reid, R.S.; Gachimbi, L.N.; Majule, A.; Lyaruu, H.; Pomery, D.; Mathai, S.; Mugisha, S. The linkages between land use change, land degradation and biodiversity across East Africa. Afr. J. Environ. Sci. Technol. 2009, 3, 310-325.

26. Newbold, T.; Hudson, L.N.; Hill, S.L.L.; Contu, S.; Lysenko, I.; Senior, R.A.; Börger, L.; Bennett, D.J.; Choimes, A.; Collen, B.; et al. Global effects of land use on local terrestrial biodiversity. Nature 2015, 520, 45-50. [CrossRef] [PubMed]

27. Marques, A.; Martins, I.S.; Kastner, T.; Plutzar, C.; Theurl, M.C.; Eisenmenger, N.; Huijbregts, M.A.J.; Wood, R.; Stadler, K.; Bruckner, M.; et al. Increasing impacts of land use on biodiversity and carbon sequestration driven by population and economic growth. Nat. Ecol. Evol. 2019, 3, 628-637. [CrossRef]

28. Coleman, F.C.; Williams, S.L. Overexploiting marine ecosystem engineers: Potential consequences for biodiversity. Trends Ecol. Evol. 2002, 17, 40-44. [CrossRef]

29. Maiti, P.K.; Maiti, P. Biodiversity. Perception, Peril and Preservation; PHI LEARNING: Delhi, India, 2017.

30. Rosser, A.M.; Mainka, S.A. Overexploitation and species extinctions. Conserv. Biol. 2002, 16, 584-586. [CrossRef]

31. Thuiller, W. Biodiversity: Climate change and the ecologist. Nature 2007, 448, 550-552. [CrossRef]

32. Mutia, T.M. Biodiversity Conservation. Paper Presented at Short Course IV on Exploration for Geothermal Resources, organized by UNU-GTP, KenGen and GDC, at Lake Naivasha, Nairobi, Kenya, 2009. Available online: http://eprints.umm.ac.id/60589/33/Similarity\%20-\%20Poedjiastutie\%20-\%20English\%20textbook\% 20Cultural\%20motives\%20Curriculum\%2013.pdf (accessed on 17 October 2019).

33. Mooney, H.; Larigauderie, A.; Cesario, M.; Elmquist, T.; Hoegh-Guldberg, O.; Lavorel, S.; Mace, G.M.; Palmer, M.; Scholes, R.; Yahara, T. Biodiversity, climate change, and ecosystem services. Curr. Opin. Envieon. Sustain. 2009, 1, 46-54. [CrossRef]

34. Pimm, S.L. Biodiversity: Climate change or habitat loss-Which will kill more species? Curr. Biol. 2008, 18, R117-R119. [CrossRef] [PubMed]

35. Bellard, C.; Bertelsmeier, C.; Leadley, P.; Thuiller, W.; Courchamp, F. Impacts of climate change on the future of biodiversity. Ecol. Lett. 2012, 15, 365-377. [CrossRef] [PubMed]

36. McNeely, J.A. Invasive species: A costly catastrophe for native biodiversity. Land Use Water Resour. Res. 2001, 1, 1-10.

37. Pimentel, D.; Lach, L.; Zuniga, R.; Morrison, D. Environmental and economic costs of nonindigenous species in the United States. BioScience 2000, 50, 53-65. [CrossRef]

38. Payne, R.J.; Dise, N.B.; Field, C.D.; Dore, A.J.; Caporn, S.J.M.; Stevens, C.J. Nitrogen deposition and plant biodiversity: Past, present, and future. Front. Ecol. Environ. 2017, 15, 431-436. [CrossRef]

39. Phoenix, G.K.; Hicks, W.K.; Cinderby, S.; Kuylenstierna, J.C.I.; Stock, W.D.; Dentener, F.J.; Giller, K.E.; Austin, A.T.; Lefroy, R.D.B.; Gimeno, B.S.; et al. Atmospheric nitrogen deposition in world biodiversity hotspots: The need for a greater global perspective in assessing $\mathrm{N}$ deposition impacts. Glob. Chang. Biol. 2006, 12, 470-476. [CrossRef]

40. Bobbink, R.; Hicks, K.; Galloway, J.; Spranger, T.; Alkemade, R.; Ashmore, M.; Bustamante, M.; Cinderby, S.; Davidson, E.; Dentener, F.; et al. Global assessment of nitrogen deposition effects on terrestrial plant diversity: A synthesis. Ecol. Appl. 2010, 20, 30-59. [CrossRef]

41. Abegão, J.L.R. Where the wild things were is where humans are now: An overview. Hum. Ecol. 2019, 47, 669-679. [CrossRef]

42. Crist, E.; Mora, C.; Engelman, R. The interaction of human population, food production, and biodiversity protection. Science 2017, 356, 260-264. [CrossRef]

43. Machovina, B.; Feeley, K.J.; Ripple, W.J. Biodiversity conservation: The key is reducing meat consumption. Sci. Total Environ. 2015, 536, 419-431. [CrossRef] 
44. Alkemade, R.; Reid, R.S.; van den Berg, M.; de Leeuw, J.; Jeuken, M. Assessing the impacts of livestock production on biodiversity in rangeland ecosystems. Proc. Natl. Acad. Sci. USA 2013, 110, 20900-20905. [CrossRef]

45. Fletcher, R.J.; Didham, R.K.; Banks-Leite, C.; Barlow, J.; Ewers, R.M.; Rosindell, J.; Holt, R.D.; Gonzalez, A.; Pardini, R.; Damschen, E.I.; et al. Is habitat fragmentation good for biodiversity? Biol. Conserv. 2018, 226, 9-15. [CrossRef]

46. Fahrig, L. Effects of habitat fragmentation on biodiversity. Annu. Rev. Ecol. Evol. Syst. 2003, 34, 487-515. [CrossRef]

47. Altieri, M.A. Green deserts: Monocultures and their impacts on biodiversity. In Red Sugar, Green Deserts. Latin American Report on Monocultures and Violations of the Human Rights to Adequate Food and Housing, to Water, to Land and to Territory; Emanuelli, M.S., Jonsén, J., Monsalve Suárez, S., Eds.; FIAN International: Halmstad, Sweden, 2009; pp. 67-76.

48. Zhou, J.; Cai, Z.-H.; Zhu, X.-S. Are endocrine disruptors among the causes of the deterioration of aquatic biodiversity? Integr. Environ. Asses. 2010, 6, 492-498. [CrossRef]

49. Jean, K.; Benmarhnia, T. Endocrine Disruptors and Biodiversity. Biological Diversity Faced with Chemical Risks: The Need for a Paradigm Shift; International Report; World Wide Fund for Nature: Paris, France, 2011.

50. Schneiderhan-Opel, J.; Bogner, F.X. The relation between knowledge acquisition and environmental values within the scope of a biodiversity learning module. Sustainability 2020, 12, 2036. [CrossRef]

51. Ramadoss, A.; Gopalsamy, P.M. Biodiversity conservation through environmental education for sustainable development-A case study from Puducherry, India. Int. Electron. J. Environ. Educ. 2011, 1, 97-111.

52. Richter-Beuschel, L.; Bögeholz, S. Student teachers' knowledge to enable problem-solving for sustainable development. Sustainability 2020, 12, 79. [CrossRef]

53. Hoffman, T.; Siege, H. What is Education for Sustainable Development (ESD). Bonn, ESD Expert-Net, Engagement Global. Available online: http://www.esd-expert.net/files/ESD-Expert/pdf/Was_wir_tun/Lehr\%20und\%20Lernmaterialien/What_is_Education_for_Sustainable_Development.pdf (accessed on 18 October 2019).

54. UNESCO. Education for Sustainable Development Goals. Learning Objectives; UNESCO: Paris, France, 2017.

55. Stapp, W.B. The concept of environmental education. Environ. Educ. 1969, 1, 30-31. [CrossRef]

56. Frick, J.; Kaiser, F.G.; Wilson, M. Environmental knowledge and conservation behavior: Exploring prevalence and structure in a representative sample. Personal. Individ. Differ. 2004, 37, 1597-1613. [CrossRef]

57. Latif, S.A.; Omar, M.S.; Bidin, Y.H.; Awang, Z. Role of environmental knowledge in creating pro-environmental residents. Procedia Soc. Behav. Sci. 2013, 105, 866-874. [CrossRef]

58. Kaiser, F.G.; Fuhrer, U. Ecological behavior's dependency on different forms of knowledge. Appl. Psychol. 2003, 52, 598-613. [CrossRef]

59. Vicente-Molina, M.A.; Fernández-Sáinz, A.; Izagirre-Olaizola, J. Environmental knowledge and other variables affecting pro-environmental behaviour: Comparison of university students from emerging and advanced countries. J. Clean. Prod. 2013, 61, 130-138. [CrossRef]

60. Hines, J.M.; Hungerford, H.R.; Tomera, A.N. Analysis and synthesis of research on responsible environmental behavior: A meta-analysis. J. Environ. Educ. 1987, 18, 1-8. [CrossRef]

61. Ogden, J.; Heimlich, J.E. Why focus on zoo and aquarium education? Zoo Biol. 2009, 28, 357-360. [CrossRef] [PubMed]

62. Moss, A.; Jensen, E.; Gusset, M. Probing the link between biodiversity-related knowledge and self-reported proconservation behavior in a global survey of zoo visitors. Conserv. Lett. 2017, 10, 33-40. [CrossRef]

63. Otto, S.; Pensini, P. Nature-based environmental education of children: Environmental knowledge and connectedness to nature, together, are related to ecological behaviour. Glob. Environ. Chang. 2017, 47, 88-94. [CrossRef]

64. Keogh, J.S. The importance of systematics in understanding the 8 biodiversity crisis: The role of biological educators. J. Biol. Educ. 1995, 29, 293-299. [CrossRef]

65. Yli-Panula, E.; Jeronen, E.; Lemmetty, P.; Pauna, A. Teaching methods in biology promoting biodiversity education. Sustainability 2018, 10, 3812. [CrossRef]

66. Lindemann-Matthies, P.; Bose, E. How many species are there? Public understanding and awareness of biodiversity in Switzerland. Hum. Ecol. 2008, 36, 731-742. [CrossRef] 
67. Fischer, A.; Young, J.C. Understanding mental constructs of biodiversity: Implications for biodiversity management and conservation. Biol. Conserv. 2007, 136, 271-282. [CrossRef]

68. Yorek, N.; Aydin, H.; Ugulu, I.; Dogan, Y. An investigation on students' perceptions of biodiversity. Nat. Montenegrina 2008, 7, 176-184.

69. Menzel, S.; Bögeholz, S. The loss of biodiversity as a challenge for sustainable development: How do pupils in Chile and Germany perceive resource dilemmas? Res. Sci. Educ. 2009, 39, 429-447. [CrossRef]

70. Lindemann-Matthies, P. The influence of an educational program on children's perception of biodiversity. J. Environ. Educ. 2002, 33, 22-31. [CrossRef]

71. Gayford, C. Biodiversity education: A teacher's perspective. Environ. Educ. Res. 2000, 6, 347-361. [CrossRef]

72. Dikmenli, M. Biology student teachers' conceptual frameworks regarding biodiversity. Education 2010, 130, 479-490.

73. Lindemann-Matthies, P.; Constantinou, C.; Junge, X.; Köhler, K.; Mayer, J.; Nagel, U.; Raper, G.; Schüle, D.; Kadji-Beltran, C. The integration of biodiversity education in the initial education of primary school teachers: Four comparative case studies from Europe. Environ. Educ. Res. 2009, 15, 17-37. [CrossRef]

74. Borg, C.; Gericke, N.; Höglund, H.-O.; Bergman, E. The barriers encountered by teachers implementing education for sustainable development: Discipline bound differences and teaching traditions. Res. Sci. Technol. Educ. 2012, 30, 185-207. [CrossRef]

75. Falkenberg, T.; Babiuk, G. The status of education for sustainability in initial teacher education programmes: A Canadian case study. Int. J. Sustain. High. Educ. 2014, 15, 418-430. [CrossRef]

76. Lindemann-Matthies, P.; Constantinou, C.; Lehnert, H.-J.; Nagel, U.; Raper, G.; Kadji-Beltran, C. Confidence and perceived competence of preservice teachers to implement biodiversity education in primary schools-Four comparative case studies from Europe. Int. J. Sci. Educ. 2011, 33, 2247-2273. [CrossRef]

77. Navarro-Perez, M.; Tidball, K.G. Challenges of biodiversity education: A review of education strategies for biodiversity education. Int. Electron. J. Environ. Educ. 2012, 2, 13-30.

78. Schultz, P.W. Inclusion with nature: The psychology of human-nature relations. In Psychology of Sustainable Development; Schmuck, P., Schultz, W.P., Eds.; Kluwer: Boston, MA, USA, 2002; pp. 61-78.

79. Dunlap, R.E.; van Liere, K.; Mertig, A.G.; Jones, R.E. Measuring endorsement of the New Ecological Paradigm: A revised NEP scale. Soc. Sci. Quart. 2000, 56, 425-442.

80. Clayton, S.D. Environmental identity: A conceptual and an operational definition. In Identity and the Natural Environment: The Psychological Significance of Nature; Clayton, S.D., Opotow, S., Eds.; MIT Press: Cambridge, MA, USA, 2003; pp. 45-65.

81. Cheng, J.C.-H.; Monroe, M.C. Connection to nature: Children's affective attitude toward nature. Environ. Behav. 2012, 44, 31-49. [CrossRef]

82. Mayer, F.S.; Frantz, C.M. The connectedness to nature scale: A measure of individuals' feeling in community with nature. J. Environ. Psychol. 2004, 24, 503-515. [CrossRef]

83. Nisbet, E.K.; Zelenski, J.M.; Murphy, S.A. The nature relatedness scale: Linking individuals' connection with nature to environmental concern and behavior. Environ. Behav. 2009, 41, 715-740. [CrossRef]

84. Geng, L.; Xu, J.; Ye, L.; Zhou, W.; Zhou, K. Connections with nature and environmental behaviors. PLoS ONE 2015, 10, e0127247. [CrossRef]

85. Liefländer, A.K.; Fröhlich, G.; Bogner, F.X.; Schultz, P.W. Promoting connectedness with nature through environmental education. Environ. Educ. Res. 2013, 19, 370-384. [CrossRef]

86. Braun, T.; Dierkes, P.W. Connecting students to nature-How intensity of nature experience and student age influence the success of outdoor education programs. Environ. Educ. Res. 2017, 23, 937-949. [CrossRef]

87. Kossack, A.; Bogner, F.X. How does a one-day environmental education programme support individual connectedness with nature? J. Biol. Educ. 2012, 46, 180-187. [CrossRef]

88. Aron, A.; Aron, E.N.; Smollan, D. Inclusion of other in the self scale and the structure of interpersonal closeness. J. Personal. Soc. Psychol. 1992, 63, 596-612. [CrossRef]

89. Tam, K.-P. Concepts and measures related to connection to nature: Similarities and differences. J. Environ. Psychol. 2013, 34, 64-78. [CrossRef]

90. Brügger, A.; Kaiser, F.G.; Roczen, N. One for all? Connectedness to nature, inclusion of nature, environmental identity, and implicit association with nature. Eur. Psychol. 2011, 16, 324-333. [CrossRef] 
91. Kaiser, F.G.; Roczen, N.; Bogner, F.X. Competence formation in environmental education: Advancing ecologyspecific rather than general abilities. Umweltpsychologie 2008, 12, 56-70.

92. Frantz, C.; Mayer, F.S.; Norton, C.; Rock, M. There is no "I" in nature: The influence of self-awareness on connectedness to nature. J. Environ. Psychol. 2005, 25, 427-436. [CrossRef]

93. Zelenski, J.M.; Nisbet, E.K. Happiness and feeling connected: The distinct role of nature relatedness. Environ. Behav. 2014, 46, 3-23. [CrossRef]

94. Cervinka, R.; Röderer, K.; Hefler, E. Are nature lovers happy? On various indicators of well-being and connectedness with nature. J. Health Psychol. 2012, 17, 379-388. [CrossRef]

95. Mayer, F.S.; Frantz, C.M.; Bruehlman-Senecal, E.; Dolliver, K. Why is nature beneficial? The role of connectedness to nature. Environ. Behav. 2009, 41, 607-643. [CrossRef]

96. Fritz, C.O.; Morris, P.E.; Richler, J.J. Effect size estimates: Current use, calculations, and interpretation. J. Exp. Psychol. 2012, 141, 2-18. [CrossRef]

97. Borenstein, M.; Hedges, L.V.; Higgins, J.P.T.; Rothstein, H.R. Introduction to Meta-Analysis; Reprinted; Wiley: Chichester, UK, 2009.

98. Bundesverwaltungsgericht. Verkehrsverbot (u.a.) für Dieselfahrzeuge in der Umweltzone Stuttgart. 2018. Available online: https://www.bverwg.de/270218U7C30.17.0 (accessed on 25 November 2019).

99. Krüger, U.M.; Zapf-Schramm, T. InfoMonitor 2018: GroKo und Migrationsdebatte prägten die Fernsehnachrichten. Media Perspekt. 2019, 2, 44-73.

100. Chauhan, A.J.; Krishna, M.T.; Frew, A.J.; Holgate, S.T. Exposure to nitrogen dioxide (NO2) and respiratory disease risk. Rev. Environ. Health. 1998, 13, 73-90.

101. Kagawa, J. Evaluation of biological significance of nitrogen oxides exposure. Rokai J. Exp. Clin. Med. 1985, 10, 348-353.

102. Radek, C. Invasive Species: How People's Activities Affect Their Knowledge. Available online: $\quad$ http://www.iiseagrant.org/NabInvader/Lakes/admin/AISstewardshipProejcts/ProjectsType/ InvasiveSpeciesPaper-Chris\%20Radek.pdf (accessed on 26 November 2019).

103. Fraser, W. Introduced Wildlife in New Zealand: A Survey of General Public Views; Landcare Research Science Series 23; Manaaki Whenua Press: Lincoln, Canterbury, New Zealand, 2001.

104. Veitch, C.R.; Clout, M.N. Human dimensions in the management of invasive species in New Zealand. In The Great Reshuffling: Human Dimensions of Invasive Alien Species; McNeely, J.A., Ed.; IUCN: Gland, Switzerland, 2001; pp. 63-71.

105. Grossi, G.; Goglio, P.; Vitali, A.; Williams, A.G. Livestock and climate change: Impact of livestock on climate and mitigation strategies. Anim. Front. 2019, 9, 69-76. [CrossRef] [PubMed]

106. Leip, A.; Billen, G.; Garnier, J.; Grizzetti, B.; Lassaletta, L.; Reis, S.; Simpson, D.; Sutton, M.A.; de Vries, W.; Weiss, F.; et al. Impacts of European livestock production: Nitrogen, sulphur, phosphorus and greenhouse gas emissions, land-use, water eutrophication and biodiversity. Environ. Res. Lett. 2015, 10, 115004. [CrossRef]

107. Bundesministerium für Ernährung und Landwirtschaft (BMEL). Daten und Fakten. Land-, Forst- und Ernährungswirtschaft mit Fischerei und Wein- und Gartenbau; BMEL: Berlin, Germany, 2017.

108. Bundesministerium für Ernährung und Landwirtschaft (BMEL). Landwirtschaft Verstehen. Fakten und Hintergründe; BMEL: Berlin, Germany, 2018.

109. European Union. Council Regulation (EC) No 834/2007 of 28 June 2007 on Organic Production and Labelling of Organic Products and Repealing Regulation (EEC) No 2092/91; Publications Office of the European Union: Brussels, Belgium, 2007.

110. Noleppa, S. Pflanzenschutz in Deutschland und Biodiversität: Auswirkungen von Pflanzenschutzstrategien der Konventionellen und Ökologischen Landbewirtschaftung auf Die Regionale und Globale Artenvielfalt; HFFA Research: Berlin, Germany, 2016.

111. Cohen, J. Statistical Power Analysis for the Behavioral Sciences, 2nd ed.; Lawrence Erlbaum Associates: Hillsdale, MI, USA, 1988.

112. Field, A.; Hole, G. How to Design and Report Experiments; Sage: London, UK, 2003.

113. Pinker, S. Enlightenment Now. The Case for Reason, Science, Humanism, and Progress; Viking: New York, NY, USA; London, UK, 2018.

114. Javornik Krečič, M.; Ivanuš Grmek, M. The reasons students choose teaching professions. Educ. Stud. 2005, 31, 265-274. [CrossRef] 
115. Powers, A.L. Teacher preparation for environmental education: Faculty perspectives on the infusion of environmental education into preservice methods courses. J. Environ. Educ. 2004, 35, 3-11.

116. World Economic Forum. Global Risks 2019, 14th ed.; Insight Report; World Economic Forum: Geneva, Switzerland, 2019.

117. Hessisches Kultusministerium. Kerncurriculum Gymnasiale Oberstufe: Politik und Wirtschaft; Hessisches Kultusministerium: Wiesbaden, Germany, 2016.

118. Hessisches Kultusministerium. Kerncurriculum Gymnasiale Oberstufe: Erdkunde; Hessisches Kultusministerium: Wiesbaden, Germany, 2016.

119. Hessisches Kultusministerium. Kerncurriculum Gymnasiale Oberstufe: Evangelische Religion; Hessisches Kultusministerium: Wiesbaden, Germany, 2016.

120. Frantz, C.M.; Mayer, F.S. The importance of connection to nature in assessing environmental education programs. Stud. Educ. Eval. 2014, 41, 85-89. [CrossRef]

121. Dutcher, D.D.; Finley, J.C.; Luloff, A.E.; Johnson, J.B. Connectivity with nature as a measure of environmental values. Environ. Behav. 2007, 39, 474-493. [CrossRef]

122. Roczen, N. Environmental Competence: The Interplay between Connection with Nature and Environmental Knowledge in Promoting Ecological Behavior. Ph.D. Thesis, Technische Universiteit Eindhoven, Eindhoven, The Netherlands, 2011.

123. Kals, E.; Schumacher, D.; Montada, L. Emotional affinity toward nature as a motivational basis to protect nature. Environ. Behav. 1999, 31, 178-202. [CrossRef]

124. Schultz, P.W.; Tabanico, J. Self, identity, and the natural environment: Exploring implicit connections with nature. J. Appl. Soc. Psychol. 2007, 37, 1219-1247. [CrossRef]

125. Samir, K.C.; Lutz, W. The human core of the shared socioeconomic pathways: Population scenarios by age, sex and level of education for all countries to 2100. Glob. Environ. Chang. 2017, 42, 181-192.

(C) 2020 by the authors. Licensee MDPI, Basel, Switzerland. This article is an open access article distributed under the terms and conditions of the Creative Commons Attribution (CC BY) license (http://creativecommons.org/licenses/by/4.0/). 